\title{
7. Corruption, Development, Chaos and Social Disorganisation: Sociological reflections on corruption and its social basis
}

\author{
John Clammer
}

Corruption is now widely understood to be one of the main distorters of effective development intervention, leading to the illegal misappropriation of aid, inefficiencies and crime in local and national bureaucracies, the failure of poverty-alleviation schemes to reach the very poorest, and general lack of access to primary health care, education, housing and clean water. High levels of corruption can distort the operation of social justice and the fair distribution of resources. Corruption is also often seen as a 'local' problem-as a form of crime that requires ethical, legal or managerial mechanisms to prevent, contain or eradicate it, or as a failure of individual morality or traditional norms when vulnerable people are placed in a position of temptation.

This chapter will advance the thesis that corruption is, in fact, a systemic problem in which whole social systems are implicated, and which is generated in large part by dysfunctions in systems themselves. In standard sociological parlance, the notion of social organisation implies the smooth running of a given social system. 'Social disorganisation' is therefore seen as its opposite or as the degeneration of a functional system. This term is, of course, relative and often substantially ideological. For example, the 'social harmony' ascribed to Singapore and North Korea perhaps represents control more than functionality. Yet we can identify with reasonable accuracy situations in which social breakdown or non-functionality is evident through its negative impact on the quality of life, particularly of the non-powerful, non-privileged or excluded members of a given society, and the expression of this non-functionality in rising levels of crime, violence and corruption (Jones-Finer \& Nellis, 1998).

This chapter should therefore be read as an exercise in social theory, not as an empirical analysis of corruption in specific cases. It is an attempt to broaden the scope and range of reference of organisational sociology in order to include within its ambit issues of development and social change, alongside its traditional preoccupation with the internal structure of organisations, particularly businesses and bureaucracies. 
The problems listed at the beginning of this chapter can reasonably be seen as examples of social disorganisation. This claim rests on the assumption that the desirable outcome of any social system is that, within reasonable limits, it satisfies the material, psychological and spiritual needs of the majority of its population without the unreasonable diversion of public resources to a minority.

In other words, a 'functional' system is not one in a state of functionalist or Parsonian 'equilibrium', which is, in fact, a rare if ever actually encountered empirical situation. A 'functional' system is one that allows a reasonably secure normal human social life to flourish and also extends the range of that life beyond the satisfaction of basic needs into areas of cultural creativity, psychic security and leisure - a point validly promoted by the now largely abandoned 'basic human needs' theory of development priorities developed in the 1980s (for example, Dube, 1984).

If societies are understood in this way then corruption is arguably not just an epiphenomenon of forms of social organisation that are manageable by better policing, moral education or institutional adaptation. Rather, corruption is a key to understanding the nature of social disorganisation in much more fundamental theoretical and empirical sociological ways, because corruption itself emerges largely from that disorganisation. The question then becomes how to think about that disorganisation in fresh ways that will both advance our understanding of the endemic occurrence of corruption and point beyond limited solutions to more systemic ones.

In this chapter I will attempt this task in four ways. First, I relate the analysis of corruption more fully than has been done before to some important aspects of contemporary social theory and to current anthropological theories of culture. Second, I explore corruption through the prism of chaos theory as a potentially creative way of investigating social disorganisation. Third, I relate corruption to systemic changes in the world system, in particular to the spread of what might be termed 'capitalist morality', the consequences of economic globalisation and its consumerist 'ethic'. Fourth, I argue that in failed or authoritarian states, there is a deliberate attack on - or progressive dissolution of - civil society and the forms of social solidarity on which it is based, and a corresponding attack on indigenous forms of morality (see also Clammer, 2004). This argument applies equally to states that have been undermined by the penetration of capitalist social relations and the economic crises caused by globalised finance, in SouthEast Asia and Mexico in the 1990s, and from 2001 in Argentina.

Although corruption has probably been a feature of human societies in every historical period, we must also face the possibility that there are distinctively modern forms and indeed forms created by modernity itself. Even as Zygmunt Bauman (1999) has argued that modernity reached its climax in the Holocaust, 
not emancipation or enlightenment, so too it might be argued that modernity has eventuated in forms of social disorganisation quite unforeseen by its architects. Such disorganisation has included escalating levels of violence, corruption and ecological degradation and the non-arrival of the 'development' that much of the world has been eagerly expecting. Or rather, the form that 'development' has taken has brought in its wake these unexpected consequences - and especially its current manifestation as globalisation, with all its multiple levels and ambiguities (Hay \& Marsh, 2000) and its impact on identities, concepts of citizenship and patterns of migration and settlement (Hudson \& Slaughter, 2007). In a kind of inversion of Norbert Elias's (2000) theory of the 'civilising process', I will argue that corruption is not accidental or contingent but an endemic and intrinsic part of the social forms created out of the macroscopic forces of modernisation and globalisation, and their highly unequal spread and penetration.

\section{Corruption and social process}

The study of corruption, rather like the parallel study of criminology, shows up the ragged edges of sociological explanation. There are several reasons for this. Corruption and its endemic nature and distribution suggest a less than pleasant view of human nature, one in fact more congenial to Hobbes than to Rousseau. Corruption calls seriously into doubt functionalist theories of human society and similar versions based on assumptions of equilibrium. Corruption suggests the need for a much more chaotic modelling of social reality than is psychologically attractive to most sociologists. It poses awkward questions for discourses of rights, social ethics, the place of values in development, democratisation and the possibility of so-called post-development as an image and model of the future (Rahnema \& Bawtree, 2003). The analysis of corruption also suggests that a new vocabulary might be needed in legal and political anthropology. We need to recognise that the systematic ignoring and distortion of both legal mechanisms and informal or 'cultural' ones by corrupt practices and procedures bring into question some fundamental assumptions. These assumptions are of 'order and continuity in everyday life' and that mechanisms of social control and dispute resolution other than law are somehow more efficient and humane (Roberts, 1979).

To make this claim is not to discount the role of culture. Many practices that might now be regarded as corrupt in the context of modernist assumptions about the nature of the state and the behaviour of public servants would, in the past, have been seen as parts of gift exchange or the natural and civilised lubrication of social relationships (see, for example, Yan, 1996). Indeed, a common problem is the normative discontinuity between the practical coexistence of 'traditional' 
and modernist social norms in the same social and political spaces, with a corresponding lack of clarity about the appropriate application of acceptable rules. The fundamental problem with a culturalist approach to corruption is, however, that it tends, as with older conceptions of culture generally, to take a somewhat essentialist approach to both the possession and the practice of culture. Paradoxically, this approach to corruption is occurring at the same time as many anthropologists are abandoning the concept of 'culture' because of its diffuseness and the impossibility of coherently defining it. Several authors have remarked that 'culture' is a strategic device not an essence-in short, that 'culture' is political (Fox \& King, 2002).

Scholars increasingly see culture as something negotiated, fluid and constantly in the condition of being constructed and deconstructed. This perspective comes much closer to a chaos model of social organisation than to older holistic and functionalist ones; however, the solution to the shortcomings of a culturalist approach is neither a total abandonment of the appreciation of cultural factors in corrupt behaviour nor the wholesale adoption of an economic approach. Rather, what is required is a new form of systems approach. This approach would combine these elements with, and into, a more accurate model of the nature of social processes. It would take account of the current context of contemporary globalised modernity and would recognise this modernity's impact on identity, subjectivities and social relations (for example, Giddens, 1991).

The possibility and desirability of attributing ethical responsibility to individuals are a given in what follows, and should not be taken as an argument against personal honesty and authenticity. My argument is, in fact, an attempt to demonstrate the complexity of the social context in which ethical decisions are taken and the extent to which those decisions are deeply influenced by the dissolution of norms.

Much corrupt behaviour on the part of individuals represents what Jean Baudrillard (2001 [1979]) would perhaps call 'seduction' - that is, not only the rational calculation of economic advantage in a situation where one thinks one will not get caught, but also, more importantly, the manipulation of values by socioeconomic institutions that systematically manufacture anomie. While Durkheim (1952 [1897]) saw anomie as a highly negative symptom of the collapse of organic and integrative values in society, one could now argue that globalised capitalist society is a huge machine for the manufacture of just that very anomie.

In fact, without naming it as such, many of the currently prominent analyses of contemporary society and culture point to exactly this conclusion. Amongst these are: from a German standpoint, Ulrich Beck's 'risk society' (1992); from a French perspective, Michel Maffesoli's vision of the collapse of the social 
structures of consumerist societies into neo-tribalism (1996); or from a British perspective, Anthony Giddens' theory of selfhood in late capitalist society (1991).

Psychological factors play a role in corruption. For example, people can enter into corrupt transactions because of the personal power that they confer, to manage their insecurities or to enhance their sense of self. But just as Durkheim was concerned to rescue sociology from psychology, so my concern is to delineate a new systems approach in which the very elements of those systems - while essential to the overall structure - are inherently unstable. This paradox of unstable stability now needs stating, explaining and applying to a theory of corruption.

\section{Unstable systems and the theory of corruption}

In introducing a collection of essays on corruption, Peter Larmour and Nick Wolanin (2001) note that 'the recent scandals surrounding the Olympic games show how reliance on the virtues of "good people", such as former athletes, is insufficient unless good systems are also in place' (p. xiv). The revelations of systematic prisoner abuse in Iraq by US military personnel, and the tragically large number of accounts of abuse in hospitals, old-age homes, schools and other contexts, drive home this point.

Situation - or location within a system, structure or organisation-as much as culture, moral weakness or personality, plays the major role in determining when and if corrupt behaviour will occur, assuming that opportunities exist. Although various organisational theories of corruption and its prevention exist (such as the so-called 'managerial' approach), what tends to be missing is an understanding of the interactive nature of subsystems with each other.

Assuming that opportunities for corruption exist in all societies, a corrupt outcome is more probable in situations of weak organisational culture, an inefficient or corrupt police force or a cowed press or one with little tradition of investigative journalism. Corrupt behaviour is likely to occur at the point where these three subsystems meet - at the point of negative synergy, as it were. In turn, these subsystems will be embedded in larger political cultures and norms of economic activity.

This proposition has significant implications for organisational sociology. A key implication is that organisational sociology should greatly expand its agenda beyond the analysis of 'normal' institutions to include dysfunctional ones. The analysis needs to incorporate fully the fact that dysfunctional events and processes constantly occur even in the most apparently 'normal' ones. 
The situation is intensified when the managerial or organisational system is subverted from the top - where the system itself is dysfunctional or corrupt, or simply lacks efficiency or the ability to implement the initiatives that it might itself generate. Such is the case in the so-called 'failed states' of central Africa, where, even if a government exists on paper, it either cannot carry out its mandate or is itself the centre of corruption (Kahl, 2006). A parallel situation can be found in Latin American states that have or are experiencing high levels of internal violence. Examples are Argentina or Chile under their recent military regimes, and contemporary Colombia, Mexico and Brazil, where much of the violence is led by the drug trade or by the extremities of social inequality and mal-development (Scheper-Hughes, 1992). Even more extreme cases can be found in those zones or states where civil war or separatism is rampant (for example, Sudan or Chechnya), or where external forces destroy a previously existing sociopolitical order with no viable plan for re-establishing order (for example, Afghanistan and Iraq), or where multilateral aid agencies impose a set of pro-market policies on a socioeconomic order ill equipped to deal with, implement or even understand them (as with International Monetary Fund intervention in Indonesia in the wake of the 1997 Southeast Asian economic crisis, or a little earlier as in Argentina and Mexico).

A theory of organisational disintegration or systems meltdown is consequently necessary. It would be nice to agree fully with Larmour and Wolanin (2001) that 'organisational integrity means being able to drill down into any part of an organisation, to any depth, and see evidence of the guiding ethics, whatever they might be' (p. xxiii). A problem arises, however, when the drilling reveals corruption at every level, encouraged by the culture of the top seeping into lower levels, where poverty and insecurity of health, food, shelter and even of life are the constant daily reality, and/or where incomes are low, erratic and unpredictable.

The nexus between corruption and these forms of violence is, I argue, a key issue. Furthermore, today all organisational cultures, whether we personally approve of them or not, are embedded in the bigger totality of globalisation and certain discourses of 'development'. It is to globalisation and understandings of development that we must also look for a deeper explanation of the endemic nature of corruption and its failure to diminish, despite decades of so-called development.

\section{Corruption, violence and globalisation}

There is well-documented evidence that the past three decades of development have raised the living standards of some, promoted the spread of consumerism 
amongst the wealthy and the corresponding emergence of new class factions, and greatly accelerated certain social trends such as urbanisation. At the same time, in many parts of the world and in particular in Africa, development has dismally failed to eradicate poverty, promote social and gender equity and increase real political participation. It has also brought in its wake unprecedented environmental degradation, climate change, resource depletion, destruction of indigenous cultures, and risk and instability (W. Sachs, 1995). Rampant crime, like corruption, seems to accompany mal-development, together with the perception and experience of high levels of inequality and unfairness, as in Brazil or in Argentina after its IMF-sponsored economic crisis. Although bringing about real increases in income in some cases, development has also promoted greater inequality in the distribution of those incomes both between and within nations (J. D. Sachs, 2009). These failures can be illustrated in many ways, with examples multiplied almost to infinity. Certainly development has promoted growth but, at best, the record is mixed and ambiguous, as apparent advances on one front mirror retreats on others. The failure of development is the root of corruption.

Parallel with material growth has gone what Ulrich Beck (1992) has aptly called the 'risk society': rising uncertainty and lack of knowledge or verifiable information about the complex environments that people must now navigate to survive daily life, and the job insecurity that comes with what is quaintly termed 'flexible accumulation'.

The notion that corruption arises when opportunity meets lack of ethics needs serious qualification. Although corruption may indeed be a perennial social problem, it can take new forms. A precise understanding of those forms is necessary to its management and control. In fact, we find three major factors in the contemporary 'corruption environment': mal-development that produces new or increasing patterns of inequality and the parallel recognition of social injustice on the part of its victims; violence and the intense psychological risks, pressures and uncertainties that such a life context generates; and capitalistled neo-liberal globalisation. I have covered mal-development in my discussion above and now turn to violence, globalisation and neo-liberalism.

\section{Violence}

Violence is frequently left out of discussions of corruption. But it is now a feature of or indeed part of the very fabric of everyday life, not only in conflict situations (Iraq, Afghanistan) or in many supposedly post-conflict ones (Kosovo, the Congo), but also in many so-called 'normal' societies (Colombia, Mexico, Brazil, the United States, and so on). Violence is particularly common in societies experiencing rapid political and economic transformations. 
Kay Warren and collaborators argue that 'heterogeneous formations of violence' have become part of the normal chaos of post-Cold War society (Greenhouse, et al., 2002; Warren, 1994). While they focus on Latin American, African and South Asian situations, the phenomena they describe are also present throughout Central Asia, the Balkans, Ireland, the Basque country and parts of the former Soviet Union. Warren's view builds on the now classic statement by Hannah Arendt (1970) that public life is being progressively colonised by violence and that we have witnessed, both domestically and internationally, the erosion of the rule of law. In this analysis, violence is the result of the complex interaction of colonial histories, new forms of identity politics (especially ethnic and ethno-nationalist forms), population displacement, land pressure, demographic growth, globalisation, neo-liberal economic policies, regional and state politics (and now presumably international ones, too) and the unintended by-products of well-meaning humanitarian and other forms of intervention.

The invasion of public life by violence has appeared in state terrorism (for example, the death squads of Argentina and Chile during their most recent military dictatorships), insurgency and counterinsurgency, peasant rebellions, the militarisation of society and the blurring of the boundaries between civilians and the military, and the loss of trust within one's own social group as well as between groups. There is a loss of solidarity, as violence unmakes both morality and community, and as boundaries and allegiances become fluid. Predatory violence and new cycles of opportunism, uncertainty, improvisation and involution replace 'traditional' or 'normal' patterns of social interaction. This process is clearly seen in the humanitarian disasters that accompany civil war, ethnic and tribal conflict and natural disasters where there is a breakdown of social organisation (Eade \& Williams, 1998). When the 'public secret' of 'acceptable' levels of violence becomes normalcy, the fabric of life is fundamentally transformed (Warren, 1994, p. 7). Chronic violence flourishes when states are weak and as allegiances, social networks and levels of trust are also weakened-just as violence also flourishes when the state is over-strong and has provoked opposition to itself.

In either condition, corruption is a by-product of - or rather is built into - the system itself. Corruption is both the means by which things routinely get done and the mechanism through which those with less power but in high-risk life contexts will attempt to protect themselves. In such conditions (as in Suharto's Indonesia), corruption becomes normal. It may even be regulated by informal but quite binding 'rules' of distribution, amounts, frequency and so forthclosely paralleling the mechanisms of the gift economies that anthropologists love to study, and in many cases replacing or displacing these mechanisms. An 
example is the Chinese notion of guanxi, which is in reality a point of contact between the economy of the gift and the economy of corruption (Gold, et al., 2002).

Also interesting is that there appears to be a convergence of forms of violence and crime across cultures. This convergence suggests that globalisation can take some unexpected and sinister forms.

\section{Globalisation and neo-liberalism}

In their list of factors influencing the rise of modern forms of violence, Greenhouse et al. name both globalisation and neo-liberalism (2002). I think that they are correct. Here we are getting closer to the root conditions of both violence and contemporary forms of corruption, and indeed of the nexus between them. Globalisation and 'development' go hand in hand and are, in a sense, expressions both of one another and of the underlying economic philosophy of neo-liberalism.

Many detailed critiques have been made of globalisation and the social impact of neo-liberalism as espoused by multilateral agencies (in particular the IMF, the World Trade Organisation and World Bank) and the politico-economic elites of many if not most modern nation-states, including some that are theoretically socialist (Greider, 1998). Market-led (or market-driven) globalisation promotes new forms of inequality, labour migration and new conditions of work (Scrase, et al., 2003). It also has a moral impact and implications for human rights and citizenship (Brysk \& Shafir, 2004). Globalisation engenders 'market cultures', as Hefner (1998) and colleagues show in an analysis that specifically exposes the connection between morality and capitalism in East and South-East Asia.

A 'market culture' in this sense is not simply a neutral ethnographic description of the operation of capitalism. The notion of 'culture' points to how capitalism transforms social relations, brings into existence new social strata, monetises what were formerly gift or cooperative rather than commoditised relationships, introduces new values (including the alien idea that time is money) and fundamentally reframes morality. Although most capitalists or advertising people might not like to name it as such, this morality is based on greed, acquisitiveness, unequal distribution of rewards (in the form of wages or of profits), the high evaluation of material success and possessions, and individualism.

While these same societies often continue to uphold traditional religious values and attempt to curb the worst excesses through law enforcement and managerial means, in reality a serious divergence exists between these mechanisms of control and actual praxis. To preach restraint in an environment in which to get rich is glorious is almost certainly to be preaching to the deaf, or at best to people who 
may compartmentalise ethics into those pertaining to the private sphere where traditional values still at least theoretically prevail, and the marketplace where they most certainly do not.

In this light, we may see market-driven globalisation at two levels or from two perspectives. On the one hand, market mechanisms create a system for the intensification of international and domestic inequalities. On the other hand, these mechanisms reshape values in the direction of hedonism, greed and competition. Market-driven globalisation is a transformative force quite on par with the historical impact of any of the great world religions. It may even exceed them, since it appears that in many respects it is the capitalist morality that prevails, even in areas where in principle commodification should not apply, as in the art world (Hughes, 1990, pp. 3-28).

In its contemporary manifestations, corruption is a product of growing inequalities, capitalist morality and endemic conflict and violence. Globalisation is the root cause - and so are the policies of the multilateral trade and aid organisations whose own neo-liberal ideology is a contributing factor. As Zoe Pearson (2001) has pointed out, their foot-dragging over identifying and addressing issues of corruption until very recently is because 'these institutions have long been linked with corrupt behaviour associated with their schemes and projects' (p. 38).

I wish to go a step further and argue that not only do individual projects generate corrupt behaviour but also the very form of development that is promoted. Thus, in the case of individual schemes, corruption should be seen as a symptom of the underlying disease (compare with Elliott, 1997). Likewise, it is commonly argued that corruption negatively affects sound governance, the outcome of elections, administrative efficiency, the deployment of government resources and the generally smooth running of the political process (see, for example, Nye, 2002). Although true, this argument assumes that corruption is an epiphenomenon of otherwise workable political structures and institutions. In a developed, democratised situation, this argument is credible. But here I am advancing a stronger case for recognising structural corruption of and within politico-social systems, and especially in the context of weak or failed states, authoritarian regimes with their corresponding lack of public transparency, and situations of endemic conflict and violence - situations where the government fails to work in the interests of the people and where there is also a meltdown of social solidarity and the normal bonds of kinship, trust and friendship. Clearly, these apparently 'extreme' situations are not present in all cases where corruption is endemic. Nevertheless, currently and in the recent past the linkage is very common. (We could add Liberia, Sierra Leone, Ethiopia, Nicaragua, much of Burma and many other cases to earlier examples.) 
Even in more politically stable contexts, high crime levels, AIDS/HIV, poverty, chronic economic uncertainty, ethnic and religious conflict, environmental stress, hyper-urbanisation and familial disorganisation can underlie the apparent political stability, which is a kind of optical illusion.

All societies - developing or 'developed' - are framed by globalisation and its impact on ethical practices via marketisation and consumerism. Although I do not in any way deny the validity of more 'local' approaches to the analysis of corruption, and the consequent formulation of locally appropriate policy and anti-corruption strategies, I am here arguing for a 'strong' approach that situates such local solutions within their larger, and indeed global, structural determinants.

\section{Structure and chaos}

When social scientists use the word 'structure', as many often do, it clearly implies order and stability. I suggest that the current international order, and the results of its impact on the domestic spheres on which it constantly impinges, is in fact essentially chaotic.

Corruption must consequently be seen not only in a transnational frame (linked to globalisation, development, marketisation, the operations of multilateral agencies and international business) but also as a by-product of chaotic systems. Although corruption in situations of violence is a clear example of this chaos, we are facing instances of a wider systemic malaise in which structural violence is endemic. And violence at any level is always chaotic.

Rather than being the guardians of rights, governments themselves often prove to be the sources of structural instability. Although many states are signatories to the UN-sponsored international convention on human rights, in practice they do not observe it. Others refuse to become signatories to universally beneficial treaties - for example, the Kyoto Protocol or the UN charter on the rights of migrant workers. Wars are prosecuted without UN sanction and without regard to the Geneva Conventions on the rights of prisoners of war, at the same time as states seek to exempt their own war criminals from prosecution by the International Court. Heads of state routinely enrich themselves with the assistance of a small number of wealthy developed countries and their lessthan-transparent banking systems.

Transnational crime itself is facilitated by the nature of globalisation and its economic structures and contributes to further undermining state sovereignty (Lupsha, 1996). Transnational crime feeds off the chaotic nature of the system 
of which it is now an integral part. Transnational crime is not simply an epiphenomenon of an otherwise functional system that requires policing or managerial remedies.

If a 'network' approach is to be taken (Warburton, 2001), a clearly necessary supplement is to recognise the transnational nature of these networks, in which even local transactions are modified or informed by globalised considerations. These networks are themselves unstable - that is, chaotic-especially in situations where trust is problematic. Warburton claims that the market is merely a simplified representation of complex networks of social exchange and social action' in which the 'general population is so used to participating in the buying and selling of material goods that the layers of social exchange that underpin such transactions are invisible and instinctive' (p. 229). On the contrary, the 'market' is a strategy, a manipulative mechanism that is far from neutral and is a prime generator of chaos, not its solution.

It is axiomatic in chaos theory that small changes in initial conditions can result in large and qualitative changes in behaviour, and that formally the same behaviour exhibits different characteristics depending on its location within the total system. Thus, local behaviour differs from global behaviour, although the two are linked or mirror each other in highly complex and often indirect ways. It is exactly in these complex interconnections (rather than in 'networks' in conventional social science terms) that the dynamic nature of a system or pattern of behaviour - in this case, corruption - resides. Or to put it differently: 'chaotic and near chaotic systems bridged the gap between macro-scales and micro-scales. Chaos was the creation of information' (Gleick, 1988, p. 260).

These perspectives suggest at least two things.

First, corruption can be seen as the product of a chaotic (cyclical, unplanned, unpredictable, risk-filled) socioeconomic system in which the very behaviour allegedly condemned by the system is in fact not only generated by it but also is its mirror and shadow counterpart. In other words, corruption is generated by the system itself and, as such, is an integral part of it. Hence corruption cannot disappear unless the system itself does, because corruption is not so much parasitic on the system as a reflection of the very system itself. Managerial solutions, better policing and ethical exhortation are thus all bound to fail in the long run, or at best to be bandaid solutions to local eruptions of a much more fundamental underlying disease.

Second, corruption is a system of information and, in many ways, can be analysed in exactly the same terms as any other information flow-in terms of access to knowledge, resources and technology; relationships between 'senders' and 
'receivers'; the sociological characteristics of the 'audience'; the redundancy and miscommunications that occur in any transmission of information; 'translation' problems and so forth.

This perspective also suggests to sociologists the parallels between the analysis of corruption and that of social movements. Both corruption and social movements are systems of communication and mobilisation. Both require-corruption in a perverse way - a 'morality' (for social movements from this perspective, see Jasper, 1997).

In assessing the possible applications of chaos theory to the social sciences, Frederick Turner (1997) has the following to say:

Likewise, in the area of social policy, the attempt to change established nonlinear systems by the use of socioeconomic laws is turning out to be disappointing. After the principled application of a trillion dollars, the 'cycle of poverty' remains untouched in the country's urban areas; indeed, it has gained strength. We may have been trying to push a string. The new nonlinear science would suggest that the answer, if there is one, may lie in a totally unexpected direction - in the emergence, perhaps, of some artistic or religious or cultural attractor that will suddenly form the basis of a new kind of market of exchange and a new dimension of interdependence. Since the application of money, which is stored and abstracted negative obligation, has proven to exacerbate the problem, or at least to leave it untouched, perhaps the problem has something to do with the direction of the flow of obligation, or of a difference between the perception of its flow and its actual flow, or with an attempt to constrain its flow in one direction or another when it should find its own way, or in a misinterpretation of the meaning of money, or with the use of obligation - money - as a tool in the first place. (pp. xviii-xix)

This view, as Turner goes on to suggest, implies both the limits of policy studies and the hollowness of much 'management science' when inappropriately applied to development situations and to the analysis of complex and dynamic social systems. It leads him to recommend that less attention be paid to 'fixing' problems and more to the general cultivation of virtue in the population. I think this recommendation is correct, although the task is difficult when, at many levels, the larger socioeconomic system itself works precisely against the cultivation of that virtue.

It is axiomatic in chaos theory that, over time, dynamic systems tend towards increased - not diminished - complexity. Sociologically, this axiom means that a system of behaviours such as corruption will not tend to diminish when certain 'needs' have been 'satisfied' by those behaviours. On the contrary, the system 
will breed more needs and corruption will ramify and spread to permeate more levels of the given society. The one major systems theorist in sociology who has really noted this, Niklas Luhmann (1990), summarises this insight as follows:

Autopoietic systems, then, are not only self-organizing systems, they also produce and eventually change their own structures; their selfreference applies to the production of other components as well. This is the decisive conceptual innovation. It adds a turbocharger to the already powerful engine of self-referential machines. Even elements, that is, last components (individuals) that are, at least for the system itself, undecomposable, are produced by the system itself. Thus, everything that is used as a unit by the system is produced by the system itself. This applies to elements, processes, boundaries and other structures and, last but not least, to the unity of the system itself. Autopoietic systems, then, are sovereign with respect to the constitution of identities and differences. (p. 3)

Complexity, then, is not just an expression of the number of parts in a system. It is a modelling of the variety of their interactions and how they can align into many possible configurations, including ones not necessarily 'predictable' from the initial conditions. In this sense, corruption is a 'self-organising' system that is nested within the larger externalities of globalisation, development and marketisation.

Complexity theory then becomes a powerful tool for linking the micro and macro levels in a non-deterministic fashion that has practical and policy outcomes. This approach is linked to other 'non-necessitarian' trends in contemporary social theory (Unger, 2001). Corruption becomes a pattern of behaviour and opportunity, not to be understood in a reductionist fashion as the outcome of certain fixed variables, but as an emergent system. As Thomas Smith (1997) phrases it: 'A complex adaptive system is a system in which interactions give rise dynamically to emergent phenomena that are resilient in the face of perturbations' (p. 55). Methodological individualism proves to be a weak framework for the explanation or understanding of corruption (amongst many other things) because it suppresses the systems dimension of social interaction and also fails to explain how an emergent phenomenon can persist even in the face of quite extreme measures to control or eradicate it. From a complexity theory point of view, what is necessary is the detailed analysis of individual dynamic social systems in which corruption occurs-just as physicists analyse discrete aspects of material reality to reveal their behaviour as chaotic systems. Issues of prediction, control and public policy do not disappear. But they are reframed in a way that points towards fresh solutions, provided that 
those solutions themselves are understood in a less deterministic and much more modest manner (Elliott \& Kiel, 1997) and point towards a sophisticated understanding of the actual mechanisms of social change (Senge, et al., 2005).

The very nature of the prevailing global system-and the acquisitiveness and undermining of communities that it produces with its compulsive consumerism - promotes social exclusion and rising levels of social inequality and poverty, including new forms hitherto not seen. It undermines democracy and contributes to environmental degradation, and creates the conditions for a globalised criminal economy (Bauman, 2004). The route to change must be radically changing the system, no longer in the direction of old-style socialism but in line with what we now know about human aspirations, the operation of complex systems and the mechanisms of social change (Capra, 2003; Harvey, 2002; Korten, 1999; Theobald, 1999). Corruption must be seen in the context of a systems approach and its eradication as a function of systems change, not of piecemeal and ultimately ineffective 'solutions'. Much the same can be said about 'development' in general and the perennial problem of why the bestintentioned policies often do not work (Black, 1999).

\section{Concluding remarks}

I believe that the approach just sketched connects the analysis of corruption to much wider issues in social theory, policy studies and development theory. Far from being a peripheral issue, the study of corruption is a critical means for uncovering much more extensive social processes, their 'breakdown' and the apparent insolubility of many of the social problems that beset contemporary societies, both 'developed' and 'developing'. Furthermore, corruption proves to be the interface, or certainly one of the main ones, between ethics and social theory. This little explored intersection is of the greatest significance. It is one of the major silences of the social disciplines, few bridges having been built here between philosophy and the social sciences (Smart, 1999).

The view presented in this chapter could be seen as pessimistic. If the outcome of dynamic systems is unpredictable, policy interventions become fruitless; however, this conclusion should not be drawn. Rather, this chapter points to the high levels of uncertainty and non-predictability in all the social sciences, including economics. In so doing, it suggests the necessity of fresh methodological and theoretical approaches that more realistically address the actual nature of the world and thereby bring together social theory and policy studies in creative new synergies.

Of course, the chapter can also be read as a critique of liberal concepts of politics, which have never successfully resolved the tensions between their 
desire for a non-corrupt politics and their encouragement of the pursuit of selfinterest. These tensions are seen here from a rather different perspective: better institutions can be part of the solution only if those institutions can successfully analyse how they themselves are caught up in larger dynamic processes of which they are often unaware. If capitalism is the economic system generated by or in elective affinity with liberalism then globalisation, the alienating effects of capitalism and liberalism with its theories of human agency lie at the root of modernist modes of corruption (Gray, 2002).

Indeed, exploring the nexus between corruption and modernity has been at the heart of my argument. Corruption has been read here not as an unfortunate deviation from an otherwise smoothly functioning socioeconomic system, but as a product of that system itself.

Within the socio-logic of market capitalism, corruption is an 'enterprise' amongst others. It is generated by the very forces that have brought about 'modernisation', 'development' and their latter-day expression: globalisation. Corruption is often distinguished from 'legitimate' enterprises - for example, the manufacture and export of weapons or dumping in the Third World pharmaceutical products that are not considered safe enough for consumption in wealthy countries. Legal fictions and conventions - not the actual social morality of these activitiescreate these disguises.

Corruption is more salient in transitional economies, either those on their way from socialism to marketisation or 'developing' economies in which the cash economy is still a new experience. Few guidelines link the older patterns of solidarity to the experience of 'everything solid melting into air' and the adoption of a morality that is attractive because it is 'modern'. Then corruption indeed appears.

While the moral sources of corruption remain as perennial as they have been throughout history, morality itself needs to be situated in the context of the contemporary forces of marketisation, modernity and globalisation. Without this siting, the nature of corruption and its potential solutions will remain forever elusive.

\section{References}

Arendt, Hannah. (1970). On violence. New York: Harcourt, Brace, Jovanovich.

Baudrillard, Jean. (2001 [1979]). Seduction (Brian Singer, Trans.). Montreal: CTheory Books.

Bauman, Zygmunt. (1999). Modernity and the Holocaust. Cambridge: Polity Press. 
Bauman, Zygmunt. (2004). Wasted lives: modernity and its outcasts. Cambridge: Polity Press.

Beck, Ulrich. (1992). Risk society: towards a new modernity. London: Sage.

Black, Jan Knippers. (1999). Development in theory and practice: paradigms and paradoxes (2nd edn). Boulder: Westview Press.

Brysk, Alison, \& Shafir, Gershon (Eds). (2004). People out of place: globalization, human rights, and the citizenship gap. New York and London: Routledge.

Capra, Fritjof. (2003). The hidden connections: a science for sustainable living. London: Flamingo.

Clammer, John. (2004). Crisis, states and the sociology of Southeast Asia: constructing and deconstructing 1997. Copenhagen Journal of Asian Studies, $20,10-31$.

Dube, S. C. (1984). Development perspectives for the 1980s. Kuala Lumpur: Pelanduk Publications for the United Nations Asian and Pacific Development Centre.

Durkheim, Emile. (1952 [1897]). Suicide: a study in sociology (J. A. Spaulding \& G. Simpson, Trans). London: Routledge \& Kegan Paul.

Eade, Deborah, \& Williams, Suzanne. (1998). The Oxfam handbook of development and relief. Oxford: Oxfam.

Elias, Norbert. (2000). The civilizing process: sociogenetic and psychogenetic investigations (revised edn). Oxford: Blackwell.

Elliott, Euel, \& Kiel, L. Douglas. (1997). Nonlinear dynamics, complexity and public policy: use, misuse and applicability. In Raymond A. Eve, Sara Horsfall \& Mary E. Lee (Eds), Chaos, complexity and sociology (pp. 64-78). London: Sage.

Elliott, Kimberly Ann (Ed.). (1997). Corruption and the global economy. Washington, DC: Institute for International Economics.

Fox, Richard G., \& King, Barbara J. (Eds). (2002). Anthropology beyond culture. Oxford and New York: Berg.

Giddens, Anthony. (1991). Modernity and self-identity: self and society in the late modern age. Stanford: Stanford University Press.

Gleick, James. (1988). Chaos: making a new science. New York: Penguin. 
Corruption: Expanding the focus

Gold, Thomas, Guthrie, Doug, \& Wank, David (Eds). (2002). Social connections in China: institutions, culture and the changing nature of guanxi. Cambridge: Cambridge University Press.

Gray, John. (2002). False dawn: the delusions of global capitalism. London and New York: Granta and The New Press.

Greenhouse, Carol J., Mertz, Elizabeth, \& Warren, Kay B. (2002). Ethnography in unstable places: everyday life in contexts of dramatic political change. Durham: Duke University Press.

Greider, William (1998). One world, ready or not: the manic logic of global capitalism. Chicago: Simon \& Schuster.

Harvey, David. (2002). Spaces of hope. Edinburgh: Edinburgh University Press.

Hay, Colin, \& Marsh, David (Eds). (2000). Demystifying globalization. London and New York: Macmillan and St Martin's Press.

Hefner, Robert W. (Ed.). (1998). Market cultures: society and morality in the new Asian capitalisms. Boulder: Westview Press.

Hudson, Wayne, \& Slaughter, Steven (Eds). (2007). Globalization and citizenship: the transnational challenge. London and New York: Routledge.

Hughes, Robert. (1990). Nothing if not critical: selected essays on art and artists. New York and London: Penguin.

Jasper, James M. (1997). The art of moral protest: culture, biography and creativity in social movements. Chicago: University of Chicago Press.

Jones-Finer, Catherine, \& Nellis, Mike (Eds). (1998). Crime and social exclusion. Oxford: Blackwell.

Kahl, Colin H. (2006). States, scarcity and civil strife in the developing world. Princeton: Princeton University Press.

Korten, David C. (1999). The post-corporate world: life after capitalism. West Hartford and Singapore: Kumarian Press and Alkem.

Larmour, Peter, \& Wolanin, Nick. (2001). Introduction. In Peter Larmour \& Nick Wolanin (Eds), Corruption and anti-corruption (pp. xi-xiii). Canberra: Asia Pacific Press.

Luhmann, Niklas. (1990). The cognitive program of constructivism and a reality that remains unknown. In Wolfgang Krohn, Günther Küppers \& Helga Nowotny (Eds), Selforganization: portrait of a scientific revolution. Dordrecht: Kluwer. 
Lupsha, Peter A. (1996). Transnational organized crimes versus the nation state. Transnational Organized Crime, 2(1), 21-48.

Maffesoli, Michael. (1996). The time of the tribes: the decline of individualism in mass society. London: Sage.

Nye, Joseph S. (2002). Corruption and political development: a cost-benefit analysis. In Arnold J. Heidenheimer \& Michael Johnston (Eds), Political corruption: concepts and contexts (3rd edn, pp. 281-302). New Brunswick: Transaction Publishers.

Pearson, Zoe. (2001). An international human rights approach to corruption. In Peter Larmour \& Nick Wolanin (Eds), Corruption and anti-corruption (pp. 30-61). Canberra: Asia Pacific Press.

Rahnema, Majid, \& Bawtree, Victoria (Eds). (2003). The post-development reader. London and New Jersey: Zed Books.

Roberts, Simon A. (1979). Order and dispute: an introduction to legal anthropology. Harmondsworth: Penguin.

Sachs, Jeffrey D. (2009). Common wealth: economics for a crowded planet. New York and London: Penguin.

Sachs, Wolfgang (Ed.). (1995). The development dictionary: a guide to knowledge and power. London and New Jersey: Zed Books.

Scheper-Hughes, Nancy. (1992). Death without weeping: the violence of everyday life in Brazil. Berkeley: University of California Press.

Scrase, John C., Todd, Timothy J., Holden, Joseph M., \& Baum, Scott (Eds). (2003). Globalization, culture and inequality in Asia. Melbourne: Trans Pacific Press.

Senge, Peter M., Scharmer, C. Otto, Jaworski, Joseph, \& Flowers, Betty Sue. (2005). Presence: an exploration of deep change in people, organizations, and society. New York: Currency Doubleday.

Smart, Barry. (1999). Facing modernity: ambivalence, reflexivity and morality. London and Thousand Oaks: Sage.

Smith, Thomas S. (1997). Nonlinear dynamics and the micro-macro bridge. In Raymond A. Eve, Sara Horsfall \& Mary E. Lee (Eds), Chaos, complexity and sociology (pp. 52-63). London: Sage.

Theobald, Robert. (1999). We DO have future choices: strategies for fundamentally changing the 21st century. Lismore: Southern Cross University Press. 
Turner, Frederick. (1997). Chaos and social science. In Raymond A. Eve, Sara Horsfall \& Mary E. Lee (Eds), Chaos, complexity and sociology (pp. xi-xxxii). London and Thousand Oaks: Sage.

Unger, Roberto Mangabeira. (2001). False necessity: anti-necessitarian social theory in the service of radical democracy. London: Verso.

Warburton, John. (2001). Corruption as a social process: from dyads to networks. In Peter Larmour \& Nick Wolanin (Eds.), Corruption and anti-corruption (pp. 221-37). Canberra: Asia Pacific Press.

Warren, Kay (Ed.). (1994). The violence within: cultural and political opposition in divided nations. Boulder: Westview Press.

Yan, Yunxiang. (1996). The flow of gifts: reciprocity and social networks in a Chinese village. Stanford: Stanford University Press. 